\title{
LAS CREENCIAS RELIGIOSAS COMO CREENCIAS COSMOVISIVAS
}

Winfried Löffler*

RESUMEN: En este artículo defiendo una visión cognitivista moderada de las creencias religiosas. Las creencias religiosas se interpretan como "creencias cosmovisivas", que explico como indispensables para nuestra práctica cotidiana y científica; sin embargo, mi lectura es distinta de las lecturas no cognitivistas de la "creencia cosmovisiva" que aparecen ocasionalmente en la bibliografía.

$$
\text { yose }
$$

\section{RELIGIOUS BELIEFS AS WORLD-VIEW BELIEFS}

ABSTRACT: In this paper, I defend a moderately cognitive account of religious beliefs. Religious beliefs are interpreted as "worldview beliefs", which I explain as being indispensable to our everyday and scientific practice; my reading is nonetheless distinct from non-cognitivist readings of "worldview belief" which occasionally appear in the literature.

PALABRAS Clave: argumento kalam, epistemología religiosa, libre certeza, teísmo. KEY WORDS: free certitude, kalam argument, religious epistemology, theism.

RECEPCIÓN: 29 de julio de 2019.

APROBACIÓN: 17 de septiembre de 2019.

Dor: $10.5347 / 01856383.0133 .000299228$

*Universidad de Innsbruck, Austria. 
Se prohíbe su reproducción total o parcial por cualquier medio, incluido electrónico, sin permiso previo y por escrito de los editores. 


\section{LAS CREENCIAS \\ RELIGIOSAS \\ COMO CREENCIAS \\ COSMOVISIVAS*}

\section{Introducción}

Comienzo con un breve análisis de una reciente contribución alemana al debate que, por un lado, insiste (con justicia) en la prioridad de las razones epistémicas a favor o en contra de las creencias religiosas, pero que, por el otro, sostiene que las creencias religiosas son creencias cosmovisivas (sección 1). Esto me lleva a explicar un sentido especial de las creencias cosmovisivas, así como su papel cognitivo (sección 2). Después, arrojo algo de luz sobre una característica epistemológica especial de las creencias cosmovisivas, a saber, la fuerte participación de la "libre certeza" en su aceptación. Exploro las implicaciones para el posible papel de los argumentos a favor de las creencias cosmovisivas, especialmente para las relacionadas con el teísmo (sección 3).

* Traducción de Carlos Gutiérrez Lozano. Artículo publicado originalmente como "Religious beliefs as world-view beliefs", European Journal for Philosophy of Religion, 10/3 (2018), DOI: 10.24204/EJPR.V10I3.2592, pp. 7-25. Traduzco "world-view beliefs" por creencias cosmovisivas basándome en las indicaciones de la Real Academia Española, que recoge tanto el término "cosmovisión" (como calco del alemán Weltanschauung) como el adjetivo "visivo". Si bien es cierto que en la internet pueden encontrarse otras opciones, como cosmovisional o incluso cosmovisionario, me parece que cosmovisivo reproduce de manera gramatical y semánticamente correcta el adjetivo alemán weltanschaulich, que está detrás de la expresión inglesa citada (N. del T.). 


\section{Beckermann acerca de las creencias religiosas}

La monografía de 2013 de Ansgar Beckermann sobre las creencias religiosas ${ }^{1}$ ha recibido una amplia atención en los círculos de filosofía de la religión de habla alemana, ya que se encuentra en una serie prominente de libros introductorios y proporciona al lector un punto de vista decididamente antirreligioso, que puede corresponder con los sentimientos de la mayoría del público al que se dirige. Sin embargo, a diferencia de muchos tratados antirreligiosos contemporáneos, el libro de Beckermann evita polémicas innecesarias y se desarrolla con argumentos filosóficos serios e informados. Y hay varios puntos en el tratado de Beckermann que también serán (o deberían ser) respaldados por pensadores religiosos. El principal es la petición de Beckermann de que se dé prioridad a las razones epistémicas para reforzar la (ir)racionalidad de las creencias religiosas. Así, Beckermann puede, por ejemplo, ahorrarse a sí mismo y a sus lectores la discusión de los argumentos de la utilidad o inutilidad de las creencias religiosas que caracterizan a muchos tratados polémicos prorreligiosos y antirreligiosos, que pueden resultar muy plausibles prima facie para muchos lectores, pero que no se sostienen filosóficamente. ${ }^{2}$ En segundo lugar, Beckermann toma como objetivo a las religiones en su mejor momento, en lugar de atacar

${ }^{1}$ Glaube, 2013, Berlín/Boston, De Gruyter.

${ }^{2}$ Tales argumentos de utilidad o inutilidad (por el lado antirreligioso, véanse, por ejemplo, los conocidos tratados de los "nuevos ateos" Dawkins, Dennett, Hitchens y Harris, y por el lado prorreligioso piénsese en los argumentos familiares de las inspiraciones culturales de las religiones y su efecto benéfico sobre la estabilidad psicológica individual) son insostenibles filosóficamente por razones obvias: en primer lugar, la cuestión (no epistemológica) de la utilidad/inutilidad de las creencias es categóricamente diferente de la cuestión (epistemológica) de su racionalidad, justificación, garantía o verdad. En segundo lugar, no hay criterios obvios para sopesar los beneficios y los daños que las creencias pueden tener a veces (por ejemplo, ¿cómo se puede sopesar la belleza de la música sacra de Palestrina y de la Catedral de san Pedro contra la crueldad de la Santa Inquisición? ¿Cómo se sopesa el rescate de los escritos de Aristóteles por parte de los eruditos musulmanes antiguos y medievales contra el terror islamista de nuestros días? ¿Es, por lo tanto, útil la creencia cristiana o musulmana en general o no?). En tercer lugar, los efectos de utilidad o inutilidad de las creencias religiosas a menudo vienen unidos a otras creencias: por ejemplo, las "guerras de religión", como los conflictos de Irlanda del Norte, suelen tener en cuenta también sus sólidas causas étnicas, económicas e históricas, y muchas veces, los beneficios de la religión florecen solo en condiciones culturales adecuadas. 
la irracionalidad de las formas pervertidas (como en la falacia del hombre de paja). ${ }^{3}$ En tercer lugar, el libro de Beckermann contiene muchas críticas bien aceptadas de argumentos y posiciones problemáticas que serían de hecho innecesarias o poco recomendables incluso para aquellos que apoyan la racionalidad de la religión: por ejemplo, el argumento de Anselmo, el argumento del diseño inteligente y la teología negativa.

Beckermann no adopta el conocido argumento carnapiano de que las creencias religiosas carecen de sentido cognitivo. Les atribuye un significado más o menos claro, pero ve dos objeciones esenciales a su racionalidad. Uno es el o los problemas del mal (en los que Beckermann argumenta que ni siquiera el problema lógico ha sido resuelto, y mucho menos el problema de la evidencia). La otra es la supuesta falta de apoyo empírico de las creencias religiosas. Considera que las creencias religiosas son empíricamente comprobables en un sentido amplio y sostiene que su puntuación es baja: la oración de petición es ineficaz, como lo es poner las insignias de san Cristóbal en la cabina del coche, usar agua de Lourdes y prácticas similares (sin embargo, cabe preguntarse si tales prácticas son realmente centrales para la religión). Una línea de pensamiento subsidiaria en el libro de Beckermann es que el otro vínculo tradicional entre nuestras creencias más empíricas y las creencias religiosas, a saber, ciertos argumentos teístas con premisas empíricas (como los argumentos cosmológicos y teleológicos), no son concluyentes. ${ }^{4}$

En resumen, Beckermann sitúa las creencias religiosas muy cerca de las creencias empíricas o incluso las asimila a creencias empíricas.

3 “Gläubige sind keine Deppen" (aproximadamente "los creyentes no son idiotas"). Beckermann, op. cit., p. 152.

${ }^{4}$ Aquí, Beckermann tiende a focalizar los argumentos notoriamente precarios y a presentar su rechazo como logros importantes, mientras que los argumentos más fuertes, como el argumento kalam, no reciben la atención que merecen. Además, las interpretaciones de Beckermann de la primera vía de Tomás de Aquino y de la apuesta de Pascal son defectuosas. Para un análisis crítico más detallado del libro de Beckermann, véase mi artículo "Weltbildsätze: Nicht beweisbar, aber auch nicht irrational", en R. Jaster y P. Schulte (comps.), Glaube und Rationalität. Gibt es gute Gründe für den (A)theismus?, 2019, Paderborn, Mentis, pp. 79-104. 
Según él, no son "creencias cosmovisivas" en el sentido de Moore. ${ }^{5}$ (Está claro que esta noción de "creencias cosmovisivas en el sentido de Moore" es la posible caracterización alternativa de Beckermann de las creencias religiosas; para más información, véase la sección 2.2.) No quiero discutir si la lectura que hace Beckermann de Moore es históricamente adecuada y solo la tomaré como está presentada. Y a diferencia de Beckermann, defenderé la tesis de que, en un sentido diferente de "creencia cosmovisiva", las creencias religiosas son de hecho mejor consideradas como creencias cosmovisivas. Como tales, no son "demostrables" en ningún sentido fuerte, pero tampoco son irracionales.

\section{Las creencias cosmovisivas y sus funciones cognitivas}

\section{Preliminares: ¿Cuál es el lugar lógico del teísmo?}

Es interesante que a las creencias teístas se les hayan asignado características lógicas muy diferentes, y por lo tanto, lugares muy diferentes en nuestro sistema de creencias. Para ilustrarlo, comencemos con un análisis (vagamente quineano) de los diversos componentes de nuestro sistema de creencias. En el siguiente diagrama, en la primera columna se enumeran algunos de estos componentes. ${ }^{6}$ En la segunda columna se anotan intentos conocidos de ubicar las creencias teístas entre estos componentes respectivos (y de justificar brevemente estas colocaciones). En la tercera columna se resumen los comentarios de Beckermann sobre estos intentos (en parte son evidentes en su libro y en parte los he extrapolado).

${ }^{5}$ Beckermann, op. cit., p. 14.

${ }^{6}$ El presente análisis no pretende ser exhaustivo. Me ocupo más detalladamente de la estructura de los sistemas de creencias en "An underrated merit of Plantinga's philosophy”, en D. Schönecker (comp.), Plantinga's 'Warranted christian belief'. Critical essays with a reply by Alvin Plantinga, 2015, Berlín/Boston, De Gruyter, pp. 65-81. 


\begin{tabular}{|c|c|c|}
\hline $\begin{array}{l}\text { Componentes de nuestro } \\
\text { sistema de creencias }\end{array}$ & $\begin{array}{c}\text { Intentos prominentes } \\
\text { de ubicar las creencias } \\
\text { teístas alli }\end{array}$ & $\begin{array}{c}\text { (Presumible) comentario } \\
\text { de Beckermann sobre estas } \\
\text { ubicaciones lógicas de las } \\
\text { creencias teístas }\end{array}$ \\
\hline Verdades a priori. & $\begin{array}{l}\text { El argumento de Anselmo } \\
\text { (siempre que sea realmente } \\
\text { a priori). } \\
\text { El argumento ontológico de } \\
\text { Gödel. } \\
\text { El argumento ontológico de } \\
\text { Plantinga. }\end{array}$ & Argumentos erróneos. \\
\hline $\begin{array}{l}\text { Creencias empíricas (de la } \\
\text { vida cotidiana y de la } \\
\text { ciencia). }\end{array}$ & $\begin{array}{l}\text { Argumentos de milagros y } \\
\text { experiencias religiosas } \\
\text { extraordinarias. }\end{array}$ & $\begin{array}{l}\text { Si el teísmo se encuentra } \\
\text { aquí, está empíricamente } \\
\text { mal fundado. }\end{array}$ \\
\hline $\begin{array}{l}\text { Creencias cosmovisivas de } \\
\text { primer tipo (no razonable- } \\
\text { mente dudosas) (Becker- } \\
\text { mann las etiqueta como } \\
\text { "tipo Moore"). }\end{array}$ & $\begin{array}{l}\text { (Probablemente:) "Wittgens- } \\
\text { teinianismo" en la filosofía } \\
\text { de la religión. }\end{array}$ & $\begin{array}{l}\text { El teísmo no puede ser } \\
\text { localizado aquí, ya que es } \\
\text { razonablemente dudoso. }\end{array}$ \\
\hline $\begin{array}{l}\text { Creencia cosmovisiva de } \\
\text { segundo tipo (razonablemen- } \\
\text { te dudosa y justificable). }\end{array}$ & $\begin{array}{l}\text { Argumentos cosmológicos, } \\
\text { teleológicos y posiblemente } \\
\text { otros. }\end{array}$ & $\begin{array}{l}\text { (Presumiblemente:) Si el } \\
\text { teísmo se encuentra aquí, los } \\
\text { argumentos a su favor son } \\
\text { muy débiles. }\end{array}$ \\
\hline $\begin{array}{l}\text { Creencias cuya única } \\
\text { función es práctica. }\end{array}$ & $\begin{array}{l}\text { La apuesta de Pascal, Kant } \\
\text { (la creencia en Dios como } \\
\text { condición para la compren- } \\
\text { sión de la moral y el deber), } \\
\text { argumentos de los beneficios } \\
\text { individuales o sociales de la } \\
\text { creencia religiosa. }\end{array}$ & $\begin{array}{l}\text { Estos son argumentos de } \\
\text { razones no epistémicas; por } \\
\text { lo tanto, son irrelevantes. }\end{array}$ \\
\hline $\begin{array}{l}\text { "Creencias” sin significado } \\
\text { cognitivo. }\end{array}$ & $\begin{array}{l}\text { (Probablemente:) Teología } \\
\text { negativa. }\end{array}$ & $\begin{array}{l}\text { Esta reconstrucción de las } \\
\text { creencias religiosas es } \\
\text { inadecuada desde un punto de } \\
\text { vista religioso, ya que los } \\
\text { creyentes rechazarían (con } \\
\text { razón) la idea de que sus } \\
\text { creencias no tienen contenido. }\end{array}$ \\
\hline
\end{tabular}

${ }^{7}$ A menudo se pasa por alto que el argumento del Proslogion 2 de Anselmo contiene una premisa empírica (y falsa): que todo el mundo, incluso el tonto, entiende la palabra "Dios", "(aliqu)id quo maius cogitari nequit", es decir, "aquello/algo más grande de lo que nada puede ser concebido". Como ya lo señaló Tomás de Aquino en Summa Theologica I, 2,1 ad 1, esto es claramente falso. 
WINFRIED LÖFFLER

Beckermann sobre las creencias cosmovisivas

de tipo Moore y por qué las creencias

religiosas no son así

Según Beckermann, una maniobra familiar para salvaguardar las creencias religiosas de la crítica empírica, es decir, declararlas como creencias cosmovisivas tipo Moore, es poco recomendable. Beckermann caracteriza las creencias cosmovisivas tipo Moore de la siguiente manera: ${ }^{8}$ 1) no admiten errores normales, es decir, son "sin alternativa"; 2) no son hipótesis, por lo tanto no son empíricamente justificables; 3) son las "piedras angulares" de la práctica epistémica del creyente y, por lo tanto, no están sujetas a duda: si alguien dudara de ellas en serio, su práctica epistémica se derrumbaría; 4) no son objeto de "conocimiento" en el sentido estricto de la palabra; y 5) gozan de aceptación general.

Beckermann sostiene que las creencias religiosas no comparten algunas de estas características, y por lo tanto no son creencias cosmovisivas de tipo Moore. Justifica esta afirmación más o menos con las siguientes razones: 1) obviamente, las creencias religiosas no son sin alternativa (ni siquiera para la persona individual); la pluralidad de religiones ofrece muchas alternativas, y los seguidores de un conjunto de creencias religiosas a menudo afirman que otras están equivocadas; 2) Beckermann ve las creencias religiosas como empíricamente comprobables en un sentido más amplio (véase arriba sobre los efectos de la oración de petición, las insignias de san Cristóbal, etc., y el pobre

${ }^{8}$ Beckermann, op. cit., pp. 9-16. Si se mira más de cerca, la dialéctica general es algo complicada aquí: Beckermann desarrolla su exposición de las creencias tipo Moore a partir del ensayo de Christoph Jäger "Wittgenstein über Gewissheit und religiösen Glauben", en F. Uhl y A. Boelderl (comps.), Die Sprachen der Religion, 2003, Berlín, Parerga, pp. 221-256. Este último se centra principalmente en Wittgenstein, adopta una postura parcialmente comprensiva con Wittgenstein y trata con Moore solo indirectamente. Por lo tanto, hay varios estratos de posibles cuestiones hermenéuticas e históricas que merecería la pena investigar (si Beckermann presenta a Jäger / Wittgenstein / Moore correctamente; si Wittgenstein realmente defendió una visión de la religión tipo Moore, si Beckermann atribuye con razón al propio Jäger un punto de vista tipo Moore, etcétera). Para la presente tarea, pongo entre paréntesis todas estas preguntas y tomo la exposición de Beckermann sobre las "creencias tipo Moore" tal como son, sin preocuparme por la idoneidad de sus antecedentes históricos. 
registro empírico de creencias religiosas); 3a) los creyentes tienen a veces dudas religiosas (y también los no creyentes a veces dudan de que pueda haber algo en la religión después de todo), y tales situaciones se asemejan a las dudas epistémicas comunes en otros campos; 3b) la práctica epistemológica normal, no religiosa, no colapsaría en absoluto si un creyente religioso considerara que sus creencias religiosas son erróneas o dudosas; 4) no existe notoriamente un consentimiento general sobre las creencias religiosas.

Como breve comentario aparte sobre las afirmaciones de Beckermann, se podría decir que tiene mucha razón. ${ }^{9}$ Las creencias religiosas no son en realidad casos de creencias cosmovisivas de tipo Moore, si es que existen. Sin embargo, hay un segundo tipo de creencia cosmovisivas en nuestros sistemas de creencias, y yo diría que las creencias religiosas deberían estar mejor ubicadas allí. En lo que sigue, examinaré estas creencias con cierto detalle.

\section{Propuesta: Hay creencias \\ cosmovisivas de un segundo tipo}

No solo nuestras prácticas cotidianas, sino también las ciencias operan según diversos supuestos y estructuras operativas extracientíficas o precientíficas que por lo general son tácitas o consideradas racionales sin problema, y que, de cualquier manera, casi nunca son cuestionadas.

-Hay ciertas creencias extracientíficas o precientíficas sobre lo que "realmente" existe y debe tomarse en serio.

-Hay ciertas estructuras conceptuales recurrentes que surgen en varios dominios.

-Las prácticas científicas están integradas en diversas prácticas extracientíficas o precientíficas.

${ }^{9}$ Excepto probablemente el punto 2, donde entra en juego la desafortunada asimilación de Beckermann de las creencias religiosas a simples creencias empíricas. Si esta asimilación fuera correcta, estaría la religión más cerca de las prácticas mágicas de lo que la mayoría de los creyentes aceptarían. Al menos para las formas respetables de religión, cosas como el agua de Lourdes y las insignias de san Cristóbal son fenómenos periféricos (o incluso embarazosos), y la oración peticionaria usualmente no se interpreta en un sentido empírico burdo como las danzas de la lluvia. 
-Y existen formas estables y exitosas de comunicación sobre estos supuestos y estructuras.

Con un poco más de detalle, nos basamos, por ejemplo:

-En una distinción tácita entre los objetos y sus atributos en varios niveles (por ejemplo, distinguimos entre los electrones y su espín, los organismos y su temperatura, las poblaciones biológicas y sus tasas de crecimiento, las galaxias y su velocidad, etcétera).

-En ciertas suposiciones que toda disciplina académica hace sobre su campo de objetos (por ejemplo, los biólogos creen que existen células, genomas, órganos, organismos, poblaciones, etc.; los matemáticos creen que existen números, teoremas, etc.; los economistas lo creen de los suministros de dinero, tasas de interés, presiones de revalorización).

-En algunos supuestos - usualmente menos claros o completossobre las relaciones entre los propios campos de conocimiento. Por ejemplo, los biólogos creen que los genomas influyen en la forma y el comportamiento de los organismos y que también puede haber ciertas conjeturas de la forma y el comportamiento al genoma; los físicos creen en los átomos tanto como en esferas, espejos y baterías; y creen que las esferas, los espejos y las baterías están hechos de átomos que influyen en sus propiedades, pero también creen que no hay una explicación completa hacia arriba o hacia abajo que vincule estos reinos.

-En nuestra capacidad para distinguir e identificar especímenes normales y anormales, estándar y no estándar de objetos y situaciones; por ejemplo, distinguimos tácitamente entre plantas desarrolladas normalmente y plantas subdesarrolladas, cultivos bacterianos bien desarrollados y moldeados, movimientos corporales coordinados y descoordinados, máquinas que funcionan y chirrían, termómetros dentro y fuera de un rango de precisión aceptado, etcétera.

-En nuestra capacidad para evaluar (y a menudo predecir) las posibilidades/imposibilidades/contingencias que están relacionadas con ciertos objetos y situaciones.

-En la suposición de un principio de causalidad (según el cual los hechos y los cambios contingentes deben tener ciertas causas o conjuntos de causas). 
-En la suposición de regularidad de una amplia gama de fenómenos; por ejemplo, la suposición de que causas similares tienen (ceteris paribus) efectos similares y viceversa.

-En nuestras evaluaciones tácitas de lo que tiene (y lo que no tiene) necesidad de explicación en ciertas situaciones y cambios de situaciones.

-En la presuposición normativa de que nuestras descripciones/explicaciones del mundo deben, en general, evitar la contradicción (o que reconocen las contradicciones como problemáticas y que necesitan una mayor clarificación).

-En “normas de colisión” tácitamente asumidas para explicaciones posibles pero contrapuestas. Por ejemplo, en el curso normal de las cosas, y siempre que no haya indicios de problemas, explicamos los movimientos de las extremidades de las personas como comportamiento intencional, digamos, como casos de causalidad del agente, en lugar de casos de causalidad ejercida por causas naturales. Sin embargo, cuando las indicaciones de problemas de coordinación y disfuncionalidad aumentan, cambiamos a explicaciones fisicoquímicas o biológicas y consideramos la influencia del alcohol, la hipoglucemia o estados similares.

Los presupuestos de la lista anterior funcionan tácitamente y casi nunca se nos ocurren explícitamente (al menos, no en el curso normal de nuestro quehacer cognitivo). Como resultado, tendemos a no formularlos como "creencias". Sin embargo, sería fácil refundirlos como creencias, al menos en el sentido disposicional de "creencia": son los contenidos a los que asentiríamos si se nos formularan las preguntas pertinentes. Estas creencias proporcionan el trasfondo cognitivo que opera en nuestra práctica real y son el objeto de nuestras discusiones, especialmente en casos en los que el curso normal de las cosas se ve perturbado, nuestras expectativas se ven frustradas, etc. Obsérvese además que algunas de estas creencias tienen un contenido principalmente descriptivo, mientras que otras tienen un fuerte contenido normativo o de deber; ejemplos de esto último son la evitación de contradicciones y la asunción de reglas de colisión entre posibles explicaciones.

Las creencias de la lista anterior gozan de un estatus peculiar en nuestra organización epistémica. Por un lado, no cumplen con las cinco 
condiciones para las creencias tipo Moore, como se expuso en la sección anterior. Por ejemplo, admiten alternativas (digamos, hay ontologías procesuales y de tropos, hay filósofos que creen en verdaderas contradicciones y hay estudiosos que cuestionan algunas de las afirmaciones lógico-ontológicas fundamentales de sus respectivas disciplinas); a veces son objeto de dudas y disputas; y cierto grado de cambio en ellas no causaría un colapso de nuestras prácticas epistémicas. Por otro lado, las creencias en cuestión no son parte de la ciencia como tal; ${ }^{10}$ por ejemplo, no son ni hipótesis ni comprobables empíricamente, por lo general no se las menciona en los libros de texto de ciencias (y si lo son, entonces nada más se las asume sin cuestionar). Pero a pesar de su condición peculiar, parece intelectualmente impecable y enteramente racional mantener estas creencias, y en general todos las mantenemos. ${ }^{11}$

\section{Creencias cosmovisivas, ciencia y naturalismo}

Como una propuesta terminológica meramente pragmática (y sobre todo para distinguirlas de las creencias tipo Moore, pero aun así dentro de ese contexto), llamemos a estas creencias "creencias cosmovisivas de segundo tipo". Entre las propuestas terminológicas relacionadas y familiares de la bibliografía de las últimas décadas se encuentran "marcos conceptuales", "imagen del mundo", "metafísica (descriptiva)" y otras. La elección exacta de la terminología no es importante, ${ }^{12}$ solo es crucial

${ }^{10} \mathrm{Al}$ menos en un sentido no expansivo y no inflacionario de las palabras "ciencia" y "científico"; véase la sección 2.4.

${ }^{11}$ Defendí la importancia de tales creencias en "An underrated merit of Plantinga's philosophy" (véase nota 8) y en Einführung in die Religionsphilosophie, 2013, Darmstadt, Wissenschaftliche Buchgesellschaft, sección 5.

${ }^{12}$ Prefiero algo más el término "creencias cosmovisivas", ya que pone de manifiesto la función unificadora y orientadora un tanto mejor que las otras propuestas terminológicas: Parece natural decir que una persona comparte más de una imagen del mundo (por ejemplo, una científica y otras más allá de ella), mientras que parece extraño decir que alguien comparte diferentes cosmovisiones. Pero como mostraré enseguida, la cosmovisión (en mi sentido) es el sistema unificador de orientación epistémicamente previo. 
tener en cuenta que "cosmovisión" no se limita al frecuente, pero estrecho sentido político-religioso-axiológico que a veces parece tener la palabra. (La postura sobre los partidos y programas políticos, los derechos al aborto y la eutanasia, la existencia de Dios y de otras entidades trascendentes, etc., a veces se denominan cuestiones "cosmovisivas"; el sentido de la palabra utilizada en el presente documento es mucho más amplio y comprende contenidos que parecerían sorprendentemente triviales y vulgares a los ojos de muchas personas.)

Digamos que el conjunto de nuestras creencias cosmovisivas (en este segundo sentido) constituye la cosmovisión extracientífica o precientífica. Aunque no hay una correspondencia completa entre las visiones del mundo de diferentes personas, de hecho hay una gran superposición entre ellas, como lo demuestran nuestras (en general exitosas) prácticas sociales comunes. Contra una tendencia frecuente a considerar las cosmovisiones como dudosas y problemáticas (en comparación con los ámbitos supuestamente perspicuos y no problemáticos de las ciencias), me inclino a apoyar la tesis de que nuestras cosmovisiones precientíficas son un medio para acceder a la realidad. ${ }^{13}$ Pero más que esto: no son un apéndice insignificante que cumple un papel secundario en los canales epistémicos más dignos (por ejemplo, las ciencias): las cosmovisiones proporcionan incluso la parte epistemológicamente más fundamental de nuestra comprensión de la realidad. Las disciplinas académicas especiales pueden ser consideradas como conjuntos de teorías y métodos específicos para problemas específicos y bien definidos que se originan en nuestra cosmovisión precientífica. Esto puede verse, por ejemplo, en las siguientes consideraciones: ${ }^{14}$ 1) nuestras cosmovisiones precientíficas proporcionan el foro donde (in globo) evaluamos el éxito o el fracaso de todo nuestro cuerpo de prácticas y teorías científicas. Si la biología, la física, etc., son buenas para algo, se juzga en última instancia con base en sus consecuencias a nivel de

${ }^{13}$ Tampoco existe una línea divisoria clara entre el segmento científico y cosmovisivo de nuestra organización cognitiva, y puede haber influencias mutuas entre estos segmentos; por ejemplo, véase Stephan Körner, Metaphysics. Its structure and function, 1984, Cambridge, Cambridge University Press.

${ }^{14}$ He leído la contribución de John Greco en este número, que defiende un punto muy similar: “Transmitting Faith (and Garbage)", pp. 85-104. 
la cosmovisión: por ejemplo, si los tratamientos médicos basados en nuestras teorías biológicas son eficaces, si las construcciones técnicas (como puentes, cafeteras, aviones y televisores) desarrolladas sobre la base de nuestras teorías físicas funcionan, etc.; 2) nuestras cosmovisiones precientíficas proporcionan el foro en el que evaluamos los casos de aplicación (in)apropiados de nuestras teorías científicas, es decir, en el que elegimos qué teorías se aplican adecuadamente en determinados casos. Regresando al ejemplo de la interpretación más adecuada de los movimientos corporales: si el comportamiento actual de una persona se explica mejor como una forma de acción (quizás algo excitada) y por lo tanto como un caso para la psicología de las personas que actúan, o si es un caso para explicaciones fisicoquímicas-biológicas del estilo del patrón de hipoglucemia, no se decide por consideraciones científicas, sino más bien por nuestras expectativas de lo que es normal o anormal a nivel de nuestra cosmovisión.

De lo anterior se deduce que el naturalismo metodológico (la tesis de que solo los métodos que serían aceptables en las ciencias son conducentes a la verdad, tanto en filosofía como en nuestros otros campos cognitivos) debe estar equivocado: las ciencias (y otras disciplinas académicas) revelan la realidad solo en el contexto de todo el "paquete epistémico", que incluye nuestra comprensión precientífica del mundo, en el que esta nos ayuda a identificar los problemas científicamente trazables y a asignar a los métodos científicos sus propios campos de aplicación. ${ }^{15}$

\section{Sobre la epistemología de las creencias cosmovisivas tipo II}

Algunas observaciones sobre el estatuto epistemológico de las creencias cosmovisivas tipo II podrían ser apropiadas. En primer lugar, debido a su papel fundamental, no son demostrables en sentido estricto (empí-

${ }^{15}$ Por supuesto, esto solo es válido si "métodos científicamente aceptables" y "naturalismo" se definen en un sentido ambicioso, no expansivo e interesante: si "ciencia" se entiende en un sentido inflacionario, es decir, como el paquete completo que consiste en la ciencia propiamente dicha más el conocimiento extracientífico, de estilo cosmovisivo, entonces casi todo el mundo sería un "naturalista" en un sentido laxo y poco interesante. 
ricamente o no), ya que cualquier prueba tendría que referirse a algo más fundamental. Sin embargo, algunas de ellas son defendibles, sobre todo por su papel omnipresente y (en general) exitoso en nuestras prácticas cognitivas, tanto científicas como cotidianas. La aparente inevitabilidad de algunas de estas creencias cosmovisivas podría incluso ser defendida por los llamados "argumentos de retorsión". ${ }^{16}$ Estos argumentos muestran que el mero hecho de negar la creencia en cuestión presupone tácitamente la creencia negada, y que tal negación conduce por lo tanto a contradicciones performativas. Ejemplos históricos famosos son la defensa de Aristóteles del principio de no contradicción (PNC) (Metafísica IV, 4) y la refutación de la afirmación "no hay verdad" de numerosos filósofos griegos, medievales y modernos. ${ }^{17}$ Cualquiera que niegue el PNC presupondría que su declaración es verdadera y que la afirmación del oponente es falsa, y por lo tanto aplicaría tácitamente el PNC. Del mismo modo, el acto de afirmar "no hay verdad" presupone la verdad de esta misma afirmación y por lo tanto la contradice a nivel operativo. Estas no son "pruebas" del PNC o de la existencia de verdades, pero sí defensas muy fuertes de las mismas. De la lista de creencias cosmovisivas en 2.3, algunas podrían invitar a una defensa por medio de argumentos de retorsión. Por ejemplo, alguien que argumentara en contra de nuestra presuposición de objetos y atributos distinguiría por su propio argumento entre su destinatario (como un objeto relativamente estable) y sus opiniones (que necesitan ser cambiadas y por lo tanto son atributos cambiantes). De la misma manera, cualquier intento de argumentar en contra de nuestra capacidad principal para evaluar las posibilidades, imposibilidades o contingencias de los objetos haría uso de esta misma capacidad (ya que se considera que el cambio de opinión deseado en el destinatario se encuentra dentro de su rango de contingencias).

\footnotetext{
${ }^{16}$ Sobre estos argumentos (a veces también llamados "refutaciones elénticas", mientras que el término "argumentos trascendentales" tiene un significado más genérico), véase Gaston Isaye, "La justification critique par retorsion", Revue Philosophique de Louvain, 52 (1954), pp. 204-233.

${ }^{17}$ Véase, por ejemplo, William C. Charron y John P. Doyle, "On the self-refuting statement 'there is no truth': A medieval treatment”, Vivarium, 31 (1993), pp. 241-266.
} 
En segundo lugar, hay propuestas plausibles de criterios de racionalidad para las creencias cosmovisivas, y ni siquiera difieren fundamentalmente de las de las creencias científicas. Inspirado por Alfred N. Whitehead, Frederick Ferré ${ }^{18}$ desarrolló cuatro criterios de racionalidad para las propuestas metafísicas: 1) consistencia lógica, 2) coherencia interna (es decir, la ausencia de fragmentos de teoría dispersos e inconexos que requerirían un salto arbitrario entre patrones de explicación), 3) relación con la experiencia, y 4) apertura a cualquier experiencia nueva. En una inspección más detallada, estos criterios podrían constituir un punto de referencia de racionalidad muy general para cualquier empresa cognitiva, pero están abiertos a especificaciones: la "relación con la experiencia" de una afirmación podría, por ejemplo, significar, en contextos científicos, la posibilidad de probar mediante consecuencias observacionales previsibles; sin embargo, para las creencias cosmovisivas podría significar un funcionamiento satisfactorio para ordenar y estructurar nuestra experiencia. La "apertura a cualquier nueva experiencia” puede significar, en contextos científicos, la validez (por ejemplo) de una teoría con respecto a una gama ilimitada de variables. De igual modo, las creencias racionales cosmovisivas deberían permitirnos integrar y dar sentido a cualquier experiencia nueva, incluso sorprendente, sin excluir arbitrariamente algunas del ámbito de lo que consideramos relevante.

En tercer lugar, aunque las creencias cosmovisivas de diferentes personas se superponen en muchos puntos (de lo contrario, el éxito general de nuestra comunicación y cooperación parecería milagroso), no necesariamente se superponen en todos. Al igual que en las ciencias, la amplia superposición de las creencias cosmovisivas y la existencia de criterios de racionalidad no excluyen cierto disenso sobre las creencias cosmovisivas. Hay, por ejemplo, varias propuestas rivales de metafísica revisionista, hay defensores y opositores de lógicas paraconsistentes y hay posturas notablemente diferentes con respecto a las

${ }^{18}$ Language, logic and God, 1961, Londres, Eyre and Spottiswoode. Mi uso de los criterios de Ferré está fuertemente influido por Otto Muck, Rationalität und Weltanschaunng. Philosophische Untersuchungen, 1999, Innsbruck-Viena, Tyrolia, pp. 41s, 242. 
opciones del teísmo, el ateísmo, el pan(en)teísmo y el agnosticismo débil y fuerte. Las opiniones discrepantes en estos y otros campos no se asemejan a meras cuestiones de gusto, ni son opciones intelectuales de carácter meramente voluntario; más bien, existen argumentos a favor y en contra de estas posiciones.

En cuarto lugar, a veces las personas también cambian de opinión sobre estos asuntos, aunque estos cambios no son ni frecuentes ni fáciles. Estos cambios tienden a llegar lentamente, preparados solo por una larga consideración; de hecho, a veces estos procesos se experimentan incluso como dolorosos: la aparente similitud con las conversiones religiosas o políticas no parece demasiado inverosímil. Esta resistencia comparativa al cambio tiene que ver con un factor que muchas veces se pasa por alto en la compleja epistemología de las creencias cosmovisivas; un factor, sin embargo, que también puede ser detectado en otros contextos: el factor de la "libre certeza". Esta se analizará en lo siguiente.

\section{Creencias cosmovisivas, libre certeza y argumentos teístas}

\section{La noción de "libre certeza", certitudo libera}

Cualquier argumento exitoso, es decir, cualquier argumento que convenza al destinatario de aceptar la conclusión, requiere dos factores. Desde el punto de vista objetivo, requiere razones que puedan ser expresadas, descritas, explicadas, etc. ${ }^{19}$ Pero también hay un requisito en el lado subjetivo, que podemos describir como la aprobación no exigible del argumento y su conclusión, la adopción o la aceptación de un argumento. Llamemos a este factor "libre certeza". A primera vista, esta libre certeza puede parecer fantasmagórica, incluso una preocupante intrusión de voluntarismo epistémico: ¿no deberían ser más bien las razones las que impulsaran nuestro asentimiento, o peor aún, todo el mundo tiene derecho a seguir cualquier argumento que desee, siempre que pueda

${ }^{19}$ En aras de la simplicidad, contemos la integridad lógica del argumento entre sus razones (en un sentido más amplio), porque la integridad lógica es algo que puede ser objetivamente reclamado, explicado, etc., y en cualquier caso no es una cuestión de evaluación subjetiva. 
llegar a producir suficiente libre certeza? ¿Es la libre certeza, por lo tanto, algo así como un remedio alternativo para argumentos que de otro modo serían malos? No, en absoluto. El factor de la libre certeza es efectivamente operativo en todos los casos de éxito argumentativo; sin embargo, en "situaciones epistémicas estándar" es apenas visible. En argumentos no problemáticos (sobre temas no problemáticos, en circunstancias no problemáticas, con interlocutores no problemáticos) la confrontación con buenas razones regularmente es suficiente para motivarnos a estar de acuerdo en una libre certeza; retener la libre certeza en tales situaciones sería visto incluso como problemático. Los argumentos no problemáticos suelen referirse a cuestiones "locales" o a cuestiones de detalle dentro de ámbitos del discurso profundamente arraigados, ya sean científicos o extracientíficos. Pero cuanto más toca un argumento las cuestiones fundamentales de un dominio, más se hace evidente el componente de la libre certeza. En cuestiones tan fundamentales, normalmente hay argumentos, pero no hay "pruebas" estrictas a la vista que puedan convencer a todo el mundo.

Un ejemplo ilustrativo puede encontrarse en los centenarios debates fundacionales de los matemáticos entre el realismo y el constructivismo/ intuicionismo sobre la existencia y la naturaleza de los números. La forma común de los debates en este campo es la siguiente: hay argumentos de ambas partes que en muchos casos han llegado a ser conocidos por cualquiera que sea competente en la materia; los argumentos de los oponentes se perciben como comprensibles; las posiciones de los respectivos interlocutores no se consideran irracionales; incluso se admite que pueden tener un punto considerable. Sin embargo, los argumentos no convencen a los oponentes respectivos. Incluso frente a fuertes argumentos a favor del realismo, los constructivistas suelen seguir siendo constructivistas, y viceversa. Desde una perspectiva externa, ningún partido puede ser llamado irracional por mantener sus respectivas posiciones. Se pueden observar debates similares sobre los fundamentos de la ética (generalmente descritos como debates entre el consecuencialismo, el deontologismo y el universalismo) y entre las ontologías descriptivas y las diversas ontologías revisionarias. 
Sin embargo, las cuestiones fundamentales con un fuerte componente de libre certeza ni siquiera son ajenas a las ciencias naturales y sociales. Un ejemplo conocido son las diversas interpretaciones de la mecánica cuántica. Otro surge en el contexto de recomendaciones conflictivas de política económica basadas en teorías económicas rivales. Por ejemplo, en la recesión económica de las últimas décadas, los partidarios y opositores de la política de bajo interés de la Reserva Federal de Estados Unidos (y otros bancos nacionales) defendieron sus posiciones con argumentos elaborados (que no parecen estar impulsados simplemente por intereses de grupos políticos simples, sino que tienen un carácter genuinamente económico). Como ocurre con frecuencia en economía, la cuestión no puede resolverse de una manera empírica simple, ya que las contingencias de la historia económica nunca proporcionan condiciones limpias, comparables y repetibles; de ahí que la cuestión parezca ser una de las suposiciones económicas profundamente fundamentales. La dialéctica en ambos casos — es decir, el de la física cuántica y el de la economía — es similar: los argumentos son mutuamente comprensibles, no todos ellos son condenados como erróneos, pero rara vez bastan por sí solos para hacer que una persona cambie de opinión.

En resumen, parece que la libre certeza se vuelve más importante cuanto más estrechamente toca un tema las convicciones y supuestos fundamentales de un área de discurso, mientras que, en cuestiones con detalles locales (abiertas al control empírico y que están insertas en otras numerosas creencias consensuadas), tiende a ser irrelevante y apenas visible. De esta manera, las cuestiones fundamentales de las disciplinas académicas se asemejan a las cuestiones relativas a las creencias cosmovisivas de tipo II.

Cómo la libre certeza se relaciona con los argumentos teístas

En la sección anterior sostuve que la relevancia de la libre certeza no se limita a asuntos religiosos y otros asuntos cosmovisivos, o incluso a asuntos filosóficos en general, sino que también es un componente indis- 
pensable de los argumentos en otros campos. Pero, por supuesto, los argumentos a favor y en contra de las creencias teístas son campos de aplicación primordiales para la libre certeza, y las creencias teístas (y sus alternativas) son ejemplos primordiales de las creencias cosmovisivas del segundo tipo. Cuando se trata de tales creencias, la duda y el disenso son obviamente posibles, y la duda religiosa se asemeja de muchas maneras a las dudas epistémicas; las creencias teístas no son sin alternativas y no son generalmente aceptadas; no son directamente comprobables empíricamente (dejando de lado las formas ingenuas y mágicas de la teología), sino que tienen cierta conexión con la experiencia y además cumplen un papel integrador u ordenador con respecto a ella (entre los ejemplos se cuentan creencias como "Dios es el creador del mundo experiencial" o "Dios es la razón última de las regularidades en el mundo").

Los argumentos a favor de las creencias teístas utilizan premisas que expresan las creencias cosmovisivas de tipo II, generalmente (por ejemplo) formas de un principio de causalidad. Aunque tales argumentos pueden partir de hechos y creencias que son (en un sentido amplio) empíricamente dados, tarde o temprano cambian del reino de las creencias empíricas o de tipo científico a un discurso sobre las creencias cosmovisivas (si no lo hicieran, el "Dios" cuya existencia tratan de establecer no sería más que un objeto muy particular en el mundo, en lugar del fundamento último del mundo). En tanto que argumentos sobre las creencias cosmovisivas, están marcadamente sujetos a la libre certeza. Por lo tanto, es mejor evitar los términos "pruebas de la existencia de Dios" o "pruebas teístas": el término "prueba" debería reservarse mejor para los argumentos cuyas premisas y cuya integridad lógica están fuera de toda duda significativa, de modo que la libre certeza desempeñe a lo sumo un papel marginal. La función potencial de estos argumentos puede caracterizarse de la siguiente manera. Aunque no sean "pruebas de la existencia de Dios" (y menos aún un instrumento para conversiones fáciles), pueden demostrar que la creencia teísta no es irracional, siempre que estos argumentos impliquen buenas razones objetivas. 
Ejemplo: el argumento "kalam"

del modelo cosmológico estándar

Como ilustración de las afirmaciones anteriores, una breve mirada a uno de los argumentos teístas más discutidos de nuestros días, el argumento kalam, podría ser instructivo. Pertenece a la familia de los argumentos cosmológicos o de contingencia (como las cinco vías de Tomás de Aquino, los argumentos de Leibniz, por ejemplo, en De rerum originatione radicali (1697), y muchos otros). Comienza con el actual modelo cosmológico estándar de un universo en expansión, el cual se remonta a una singularidad inicial hace aproximadamente 14000 millones de años (es decir, un estado físico excepcional en el que ciertas cantidades llegan a cero o al infinito y las leyes naturales aún no son aplicables). William Lane Craig lo ha propuesto y defendido poderosamente contra las objeciones en numerosos libros y artículos bien conocidos. ${ }^{20}$ La reconstrucción informal presentada aquí está fuertemente inspirada por Craig. He añadido un breve comentario justificativo después de cada premisa e inferencia.

1. Todo lo que tiene un comienzo en el tiempo tiene causas de su existencia (principio metodológico, ubicuo excepto en casos marginales).

2. El universo tiene un comienzo en el tiempo (premisa “empírica”, del modelo cosmológico estándar).

3. Por lo tanto, el universo tiene causas de su existencia (de 1 y 2).

4. Existen dos patrones básicos de explicación causal: la explicación en términos de las causas regidas por las leyes de la naturaleza y la explicación en términos de la acción personal (premisa de la filosofía de la ciencia).

5. Las causas del universo no están gobernadas por las leyes de la naturaleza (del modelo cosmológico estándar: no hay explicaciones en términos de ley en la singularidad inicial).

${ }^{20}$ Véase W. L. Craig, The kalām cosmological argument, 1979, Londres, Macmillan (hay varias ediciones nuevas); W. L. Craig y J. D. Sinclair, "The kalam cosmological argument", en W. L. Craig y J. P. Moreland (comps.), The Blackwell companion to natural theology, 2009, Chichester, Blackwell, pp. 101-201; W. L. Craig, Reasonable faith. Christian truth and apologetics, 2008, Wheaton, Crossway (Fe razonable. Apologética y veracidad cristiana, 2017, Salem, Publicaciones Kerygma, trad. de Jorge Ostos). 
6. Por lo tanto, hay causas personales del universo (de 3, 4 y 5).

7. Es ontológicamente más plausible asumir que el universo tiene exactamente una y no una multiplicidad de causas (Una premisa sugerida por el modelo cosmológico estándar [iel universo comienza en un punto!] y consideraciones de parsimonia ontológica: para un comienzo en un punto, una multiplicidad de causas sería inverosímil).

8. Si el universo tiene una causa de su existencia, esta debe — más allá de la personalidad — tener algunos atributos adicionales: sin comienzo, poder, sin cuerpo, etc. (Craig aporta argumentos detallados para esta afirmación. La idea central es la siguiente: una explicación verdaderamente definitiva del universo no debe compartir los rasgos del explanandum).

9. Por lo tanto, hay exactamente una causa personal del universo con estos atributos (de 6, 7 y 8).

10. La única causa personal con estos atributos tiene similitudes sustanciales con el "Dios" de las religiones teístas (propuesta de identificación).

11. Por lo tanto, hay exactamente un Dios en el sentido de las religiones teístas (de 9 y 10; QED).

La reconstrucción anterior no pretendía ser una entrada a una discusión detallada del argumento. ${ }^{21} \mathrm{El}$ objetivo es simplemente preparar e invitar a que se hagan las siguientes observaciones: 1) el argumento tiene siete premisas $(1,2,4,5,7,8,10)$ de las cuales muchas son muy plausibles y ninguna es obviamente inverosímil; 2) ninguna de estas premisas representa un espécimen claro de una creencia propiamente "científica" o puramente cotidiana; más bien, cada premisa representa creencias que están mejor subsumidas bajo el tipo II de creencias cosmovisivas; 3) la mayoría de las premisas gozan incluso de un consentimiento amplio, pero no completo; para algunas, el consentimiento es explícito (como en el caso de la premisa 2); para otras es más bien

${ }^{21}$ También doy por sentado que la lógica del argumento puede ser reconstruida por medios bastante simples de lógica elemental predicativa. 
un consentimiento tácito que se desprende de su aplicación práctica (para las premisas 1 y 4, por ejemplo, la aplicación es casi ubicua); 4) todas estas premisas pueden estar o han estado respaldadas de hecho por argumentos (en parte muy sólidos), pero ninguna está completamente fuera de toda duda; 5) por lo tanto, cada premisa está hasta cierto punto sujeta a la libre certeza.

Debido al importante papel de la libre certeza, el argumento kalam no es una "prueba" en sentido fuerte, sino un argumento que procede dentro de un contexto de creencias cosmovisivas que pueden mostrar que la creencia teísta es racional. Otro punto que cuenta a favor de la racionalidad de la creencia teísta es el siguiente: El argumento no presupone una definición ex ante de la noción de "Dios" (que podría ser un punto de disputa en sí mismo), sino que conecta esta noción con varias creencias cosmovisivas que están ampliamente difundidas también entre pensadores no teístas. A partir de estas creencias, el argumento reconstruye los atributos del explanans causal del universo mediante una estrategia explicativa reductiva. Solo al final (paso 10) la propuesta identifica a este explanans con el Dios del teísmo. ${ }^{22}$ Por supuesto, este paso de identificación es también una cuestión de libre certeza.

\section{Conclusión}

Nuestra investigación ha demostrado que existe una importante capa de creencias racionales entre las creencias lógicas y "científicas" de buena reputación (así como las creencias de otras disciplinas académicas) y los campos de mala reputación, que van desde asuntos de gusto hasta creencias poco claras y simples tonterías. Las etiqueté como "creencias cosmovisivas tipo II" y argumenté que parece más plausible y más apropiado para la autocomprensión de los creyentes (y no creyentes) ubicar allí las creencias teístas (y no teístas). Por un lado, esto elimina la creen-

${ }^{22}$ Esta estrategia, por cierto, tiene un ancestro histórico en el paso final, a menudo pasado por alto, de las cinco vías de Tomás de Aquino: "et hoc omnes dicunt Deum" / "y a esto todos le dicen Dios". 
cia teísta de aquellas partes de nuestro sistema de creencias que se resisten a la objeción, pero también de aquellas que son a-racionales; por otro lado, desde este punto de vista las "pruebas" fuertes para el teísmo no parecen estar al alcance. Sin embargo, mi propuesta nos da una fuerte opción para reconstruir la racionalidad y la defensa de las creencias teístas. Este es un resultado significativo, dados los veredictos generalizados de que la creencia teísta es clara y evidentemente irracional. ${ }^{23}$

${ }^{23}$ Estoy en deuda con Katherine Dormandy (de soltera Munn) por sus numerosos comentarios constructivos sobre una versión anterior de este documento. 